\title{
TRADIÇÃO E MODERNIDADE NA POESIA DE APPARÍCIO SILVA RILLO, DE 1959 A 1983
}

\author{
Lisana Bertussi
}

\begin{abstract}
RESUMO: Analysis of Apparício Hissing Rillo's poetry, one of the most important and popular regionalism poets from Rio Grande do Sul state, a member of the gauchesca's literature system, i. e. the one that takes place in the privileged countryside area - the pampa gaucho, where the main character is the farm worker - o peão, and emphasizes the style of the regional language. The aim of the enquiry is to observe the amount of Modernism influence in his literary work since the sul rio-grandense regionalistic movement is not opposed to the national spirit which endorses it. Additionally it's of our interest the modernism of the language.
\end{abstract}

PALAVRAS-CHAVE: Poesia, Regionalismo, Regionalidade, Modernidade.

No mundo globalizado, cada vez mais se enfatiza a necessidade da discussão sobre a regionalidade, forma de reagir à pasteurização da cultura universalizada, segundo Ruben Oliven (1992), antropólogo gaúcho que se tem dedicado a esse tema. O Regionalismo sul-rio-grandense pode ser visto nessa perspectiva: como afirmação dos valores regionais em oposição à massificação. Não fosse por esse aspecto relevante, ainda, a Literatura regionalista do Rio Grande do Sul foi importante tendência no percurso de busca de autonomia de nossa produção literária, a qual, mesmo que com atraso, sempre esteve balizada pelos movimentos nacionais. Daí meu interesse em abordar essa produção literária.

Ressalte-se, por outro lado, a tendência conservadora forte de todas as manifestações do Movimento regionalista gaúcho, que, não gratuitamente, tem corrente intitulada Tradicionalismo. Esse aspecto precisa ser levado em conta, quando se pensa em refletir sobre o Modernismo e seus reflexos na produção literária regionalista sulina, que Guilhermino César (1971) intitulou gauchesca. Esse será o foco de minha reflexão.

Numa palestra intitulada A perspectiva do olhar regionalista: do cancioneiro popular à Modernidade, proferida na Universidade Federal do Rio Grande do Sul, no Seminário A poesia contemporânea vista do Rio Grande do Sul, realizado em julho de 1995, e, posteriormente publicada nos Cadernos de Pesquisa da UCS (1998), já pensei em que medida os poetas regionalistas do início do século e da década de 70 foram tocados pelas rupturas propostas pelo movimento do início do século. Tratei de mostrar como o primeiro grupo, que chamei modernista - usando terminologia de Alfredo Bosi (1976) - representado por Ramiro Barcelos, Augusto Meyer, Aureliano de Figueiredo Pinto e João Otávio de Nogueira Leiria, ainda é pouco influenciado pelas novas propostas de modernização, com exceção do último poeta, que já é extremamente original e pode ser considerado como um marco limite entre tradição e modernidade. Num grupo, que chamei contemporâneos - também parodiando Bosi - reuni: Sílvio Duncan, Appparício Silva Rillo, Jayme Caetano Braun, Luiz Coronel e os poetas da Califórnia.

Hoje, interessa-me recortar, apenas, o poeta Apparício Silva Rillo e sua poesia de 1959 a 1983, para mostrar de que forma sua produção, que inicia por ser mais conservadora e tradicional - o que não a impede de ser muito popular, obedecendo aos estereótipos do Regionalismo -, vai evoluindo para novas formas e perspectivas inovadoras de olhar poeticamente velhos temas da gauchesca.

Apparício Silva Rillo é porto-alegrense, nascido em 1931, embora tenha afirmado, muitas vezes, ter São Borja por adoção. Tem sua obra poética publicada de 1959 a 1986. São 27 anos de poesia que

Professora da Universidade de Caxias do Sul (UCS), Rio Grande do Sul. 
podem muito bem demonstrar um percurso evolutivo na direção da inovação. Por isso, ainda que recortando um período menor, marcado pelas obras que considero mais significativas para demonstração do processo modernizante, examinarei seus passos, através das publicações apresentadas em ordem cronológica, a seguir. O poeta inicia com Cantigas de tempo velho (1959), reeditado em 1978, com um prefácio intitulado "Uma palavra do autor", no qual ele demonstra ter plena consciência de seu percurso evolutivo, pois vê criticamente essa poesia inicial. Observe-se: "Cantigas de tempo velho e Viola de Canto largo não seriam reeditadas. Pelo menos se a decisão dependesse de mim... parecem-me, hoje, carecer de um melhor cuidado formal, de um mais acabado tratamento de estilo, de aprofundamento e escolha mais acurada de temas" (CTV, p. 11) ${ }^{1}$.

No entanto, esse livro de poemas tornou-se muito popular, talvez, por um lado, justamente por não oferecer desafios ao horizonte de expectativas dos leitores, acomodados no tradicional universo conhecido, configurado pela poesia regionalista, em que os mesmos temas de sempre são reprisados, ou seja, se fala do pala, do galpão, do violão, do cusco, da gaita, da carreta, do matungo, da faca, da chinoca, e com uma linguagem que pouco, ou nada, apresenta de original; talvez, por outro lado, porque, ainda que o poeta não se tenha dado conta, a simplicidade do poema é naturalmente simpática ao leitor pela autenticidade da linguagem estilizada. Destaque para "No bolicho", um dos poemas mais declamados nos CTGs desse Rio Grande afora, repetindo o tema do "borracho" que afoga na canha as mágoas da rejeição amorosa. Observe-se:

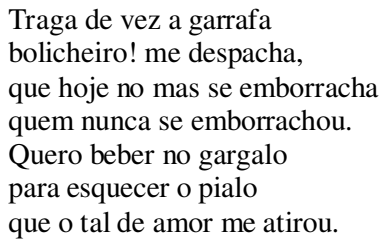

Sou índio duro de queda mas fui pegado de jeito bateu-me a argola no peito e ali no mais me planchei. Sempre fui solto de pata mas nessa volteada ingrata num tacuru tropecei.

Sucede que eu não sabia quanta manha se requer pra se correr com mulher na cancha reta do amor. Desci confiado pra raia... perdi pro rabo de saia sem sair do partidor!

Caí num tiro de laço de um olhar de china atrevida, que embuçalou minha vida na armada negra das tranças, pra depois de ter-me preso marcar-me com seu desprezo na picanha da esperança.

Desprezo não há quem cure, não há remédio que impeça, não há reza nem promessa que lhe conserte o estrago Por isso seu bolicheiro pra aparceirar o primeiro ponha no mas outro trago! (CTV, p. 67)

\footnotetext{
${ }^{1}$ Vamos, de ora em diante, usar siglas para os nomes das obras do autor, quando usarmos citaçoes, ou seja: CTV para Cantigas de tempo velho, VCL para Viola de canto largo, CV para Caminhos de viramundo, PV para Pago vago, IR para Itinerário de Rosa, AP para Alma Pampa e 30 AP para Trinta anos de poesia.
} 
Está aqui configurado o tradicional tema da rejeição amorosa, com imagens colhidas no universo do campeiro, tendência que vem desde o cancioneiro popular, com ênfase para as lides com o cavalo, no qual o amante se metamorfoseia. No contexto do poema, em que a linguagem popular tem prevalência, pois o poeta, que sempre foi "solto de pata", tropeça "num tacuru" e cai "na armada negra das tranças", nem soa vulgar que ele diga também que foi marcado pelo "desprezo na picanha da esperança".

Viola de canto largo, de 1965, com terceira edição em 1979, também é reeditado com ressalvas do autor, que agora começa a dar crédito à popularidade de sua obra, o que funciona como argumento para se permitir mais uma edição: "[...] Depois de editado, o livro não mais pertence ao autor. $\mathrm{O}$ julgamento popular adona-se dele, dá-lhe trânsito ou o esquece na poeira das estantes. Por isso - e não mais do que isso - só posso aceder em que, pela terceira vez "Viola" (sic) reencete seu caminho [...] (VCL, p. 5).

É interessante que Apparício comece a prestar atenção à recepção de sua poesia, que, como ele diz, "transita" pelo círculo do público regionalista. Esse é um texto composto por um conjunto de romances, ou seja, poemas narrativos, muito ao gosto do contar causos, típico dos gaúchos. Talvez venha também daí sua aceitação. São eles poemas narrativos como: "Romance da mulatinha", "Romance de João Guará", "Romance de João da gaita", entre muito outros, nos quais desfilam tipos campeiros à feição tradicional da poesia gauchesca e, de resto, de toda a Literatura regionalista que, por definição, prefere o tipo ao caráter individual.

Não curiosamente, o autor, sempre preocupado com os aspectos estilísticos de sua produção literária, inseriu, nessa publicação, um poema que já prenuncia sua inovação nos livros posteriores, pois aproveita experimentações da tendência da poesia concreta, além de fazer ótima estilização da oralidade, com onomatopéias, oportunas para a criação do clima de festa popular. Observe-se o poema "Nossa Senhora dos navegantes no seu dia de festa no Passo de São Borja":

Festa no rio.

O rio Uruguai está corado de contente.

$\mathrm{O}$ rio está trêmulo de ventos e ansiedade.

Vai receber Nossa Senhora dos Navegantes

sua madrinha boinha

que ele só vê uma vez em cada ano.

E Nossa Senhora vem

da Capela centenária.

Não pesa nem um tiquinho

No ombro dos marinheiros.

Vem toda repartidinha

no coração dos devotos

- cada qual trazendo um pouco

não pesa para ninguém.

Chhhhhhhhhhhhhhhhh - à cum pão!!!!

A molecada corre para apanhar a vareta

Que desprendida da carga do foguete

vem

d

o

arranhando...

o esmalte do céu. (VCP, p. 69-70)

Em Caminhos de viramundo, de 1979, já aparecem temas novos, como a inquirição sobre o significado da existência humana, a preocupação com o social, com ênfase no motivo da prostituição e na amargura do gaúcho, pelos danos causados à tradição, pela chegada do progresso no campo. Sob o ponto de vista formal, há um avanço muito significativo na direção de uma maior elaboração sonora e na riqueza da imagística, que, ainda trazendo elementos do universo campeiro, lhe dá novas nuanças com associações imprevistas e originais. Observe-se o poema "Desafio": 
Há um potro dentro de mim, pedindo cancha.

Sinto-lhe o bater do coração inquieto

Como um tambor a rufar em véspera de peleia braba.

No meu olhar o seu olhar de fogo se confunde na ânsia de devassar a vastidão de todos os caminhos que os seus cascos de asas e bronze não pisaram.

Potro de sangue ancestral,

telúrico em seu ímpeto selvagem,

maior porque contido no seu lance

como um cartucho que sente o gatilho pronto para o tiro.

Tudo que fica além de meu passo de nômade prisioneiro, tudo que não alcança o meu braço de músculos dormidos, tudo o que meu olhar não pressente na distância

- isso tudo a chamá-lo,

tudo a chamá-lo

como um toque de cincerro no silêncio da noite.

Seus ouvidos de animal selvagem

são sensíveis ao apelo da distância,

ao apelo da noite,

ao grito dos que rompem cancelas e aramados

para abrir a golpes de audácia o seu caminho de aventuras.

Há um potro dentro de mim, pedindo cancha...

No laço de chegada,

que fica sempre além,

e ainda mais além,

o sol não se põe nunca,

para vestir de ouro os que tiveram pata

para engolir todo o estirão da raia

que é um desafio de léguas pela frente.

Mas como custa arrebentar o laço

Do andarivel de partida desta cancha! (CVM, p. 49)

Veja-se que inovadora a utilização da tradicional imagem do "potro", aqui retemperada por uma nova perspectiva, pois o cavalo é alegoricamente o lado buscador do homem, "há um potro dentro de mim pedindo cancha"; é também sua possibilidade de amadurecimento e potencialidade de luta, pela libertação, nessa "ânsia de devassar a vastidão dos caminhos", ou na necessidade de procurar "tudo o que fica além do (seu) passo de nômade prisioneiro", em que o paradoxo acentua a força telúrica de emancipação, irmanada no "grito dos que rompem cancelas e aramados/para abrir a golpes de audácia o seu caminho de aventuras". E o poeta considera, sem desanimar, que muito custa "arrebentar o laço/do andarivel de partida desta cancha”.

É também muito bem elaborada a sonoridade dos versos, em que o uso das aliterações, em explosivas, alegoriza o compasso do trote mais duro do cavalo, como em: "Há um potro dentro de mim pedindo cancha/sinto-lhe o bater do coração inquieto/como um tambor a rufar em véspera de peleia braba", com ênfase para a motivação das palavras: "potro", "cancha", "bater", "inquieto", "tambor","rufar", "peleia"; ou as nasais e sibilantes, que parodiam os ritmos mais suaves de uma cavalgada, como em: "No meu olhar o seu olhar de fogo se confunde/na ânsia de devassar a vastidão de todos os caminhos/que os seus cascos de bronze e asas ainda não pisaram", com ênfase para "ânsia", "caminhos", devassar", "bronze", "asas". Pelos motivos apontados, não há dúvida de que Apparício Silva Rillo está atingindo a maturidade modernista nesse Caminhos de viramundo.

Pago vago, de 1981, que para mim é o ponto alto da poesia do autor, divide-se em três segmentos "Raízes", "Tronco e Ramada" e "A flor e o fruto" e poetiza momentos de reflexão filosófica, permeados pela consideração sobre as modificações irreversíveis da paisagem campeira, com a chegada da tecnologia e o progresso. Também aqui o social é preocupação enfática e se fala das raízes épicas da raça, mas a relação do homem com sua querência é elaborada de forma extremamente original, dando novas nuanças a esse velho tema do gauchismo. Excelente exemplo é o poema que dá nome ao livro: "Pago vago". Observe-se: 
Vago é meu pago.

Este que trago,

Cicatriz em mim.

Raiz de minhas íntimas origens,

Veio subterrâneo de onde vim.

Vago é meu pago.

Este que trago,

Em músculos e ossos.

Inteiro como foi porque é memória,

Flor de perenidade entre destroços.

Vago é meu pago.

Este que trago,

como sombra e manto.

É meu destino a cruz de sustentá-lo

nos alicerces de vento do meu canto. (30 AP, p. 112)

Já é uma ruptura modernizante a ambigüidade com que o poeta abre seu poema: "Vago é meu pago", em que "vago" pode significar vazio, porque o gaúcho precisou emigrar, ou, ainda, a imagem do pago já anuviada para o campeiro que, nas agruras da cidade, quase esqueceu de seus contornos. Ora, esse é um tema caro ao Regionalismo: a saudade da querência. Mas com que originalidade Apparício faz emparelhar com a "raiz" das "íntimas origens" a "cicatriz" que o homem rural traz "nos músculos e ossos", "inteiro... porque é memória". E que fragilidade pode estar num "canto" de poeta que tem "alicerces de vento"!

Muito bem trabalhada a sonoridade do texto, com a dor aguda da saudade alegorizada nas asssonâncias em "i”, em palavras como "cicatriz", "raiz", "íntimas", "vim”, em que a frieza cortante é evidente. Também valiosas as assonâncias em "a", em momentos como "vago é meu pago", com sua possibilidade de remeter à amplidão de um pago já distante para o gaúcho saudoso. Ainda, o poeta se permite o poema condensado, proposto pelos modernistas, sintético e com alto grau de poeticidade, tão diferente da prolixidade tradicional dos poemas regionalistas.

Em Itinerário de Rosa, de 1983, que o poeta chamou de "novelinha em versos, com harmonias e quebradas de tango passional", conta-se a história da degradação social de Rosa, moça do campo, que acaba prostituta na cidade. O autor diz, num prefácio intitulado "Por necessário" (IR, p. 5), que resolveu "emprestar trânsito em (seus) versos à menina que nasceu num rancho de pau a pique; que sonhou com o mundo que ficava além da medida de seus passos; que, na garupa do gaudério, foi carregada do campo para a penúria do abandono; que, como um anjo de asas negras, livrou-se do bordel de quinta para a "casa montada'. E aí a (deixou.)". Observe-se o poema "Romance de Rosa plena", um dos mais bem elaborados do conjunto:

\footnotetext{
A Rosa que foi de muitos agora é Rosa de um só. China de casa montada na ruazinha arredada onde macegas e ventos bailam vestidos de pó.

Vozes lhe batem à porta e a chamam de "rapariga". Rosa disfarça, não liga, cerra as cortinas e os olhos se adentra dentro de si. Custou-lhe chegar ali: - na sala quatro por quatro, no quarto quatro por três, no dar-se sem entregar-se, a quem a toma e em troca lhe paga as contas do mês.

[...]

Semente ao vento, plantou-se quem fora terra de planta para a semente dos machos. Agora, só um a tem
} 
quando vem e quando a quer.

Só um se aninha em seus peitos

para exercer o direito

de dono de uma mulher.

Mas a noite é de recuerdos,

É de silêncios que gritam,

De arremessos e uivos

De cães danados no seio.

E ele, seu dono,

não veio.

Não veio para tomá-la

Feri-la de pluma e garras,

rasgar-lhe o ventre onde canta

todo um verão de cigarras.

E Rosa, transfigurada,

por ventos de danação,

volta a ser quem Rosa era,

desnudo o corpo vestido

por lençóis de solidão. [...] (IR, p. 35)

Veja-se que o poeta nomeia a prostituta, ironicamente, como "Rosa", que pode representar uma antítese, uma vez que nada há de flor e positividade no "itinerário" dessa mulher campeira, que agora é "China de casa montada", mas numa "ruazinha arredada/onde macegas e ventos bailam vestidos de pó", indiciando o quanto as aspirações da mulher são restritas. Ainda, acentua-se o seu papel de objeto "na sala quatro por quatro/no quarto quatro por três/no dar-se sem entregar-se/a quem a toma e em troca/lhe paga as contas do mês", "exerce(ndo) o direito/de dono de uma mulher". E, ainda, a falta do homem, em "E ele seu dono,/não veio/Não veio para tomá-la,/feri-la de pluma e garras”, pode recolocar a moça numa enfática situação de penúria emocional e afetiva, marcada pela solidão, ou seja: "E Rosa transfigurada,/por ventos de danação,/volta a ser quem Rosa era,/desnudo o corpo vestido/por lençóis de solidão".

São muito bem elaboradas as imagens antitéticas, as associações imprevistas, ao gosto dos modernistas, e a motivação sonora, feita da agudez das assonâncias em "i", ou da agressividade rascante das aliterações em "r", ou das explosivas como o "t", o "d", o "c", como em "Mas a noite é de recuerdos,/ é de silêncios que gritam,/de arremessos e uivos/de cães danados no seio", ou em "Não veio para tomála,/feri-la de pluma e garras, rasgar-lhe o ventre onde canta/todo um verão de cigarras", onde fica claramente acentuada a potencialidade de calor humano de que Rosa seria possuidora, não fossem as condições sociais adversas de que é vitimada.

Parece-me que esse esboço de percurso, representado pelo exame parcial das obras de Apparício Silva Rillo, de 1959 a 1983, basta para demonstrar, por ora, que as influências do movimento modernista chegam tardiamente à poesia regionalista gauchesca, mas não deixam de marcá-la positivamente em direção à renovação dos tempos modernos.

\section{BIBLIOGRAFIA}

BERTUSSI, Lisana. Literatura gauchesca. Do cancioneiro popular à modernidade. Caxias do Sul: EDUCS, 1998.

BERTUSSI, Lisana. A perspectiva do olhar regionalista: do cancioneiro popular à modernidade. Cadernos de pesquisa da UCS, Caxias do Sul, n. 2, v. 6, 1998.

BOSI, Alfredo. História concisa da Literatura Brasileira. São Paulo: Cultrix, 1976.

CESAR, Guilhermino. História da Literatura do Rio Grande do Sul. Porto Alegre: Globo, 1971.

OLIVEN, Rubem George. A parte e o todo: a diversidade cultural do Brasil-nação. Petrópolis: Vozes, 1992.

RILLO, Apparício. Cantigas de tempo velho. 3.ed. Porto Alegre: Martins, 1981.

RILLO, Apparício. Viola de canto largo. 3.ed. Porto Alegre: Martins, 1983.

RILLO, Apparício. Caminhos de viramundo. Porto Alegre: Martins, 1979.

RILLO, Apparício. Pago vago. Porto Alegre: Martins, 1981. 
RILLO, Apparício. Itinerário de Rosa. Porto Alegre: Martins, 1983.

RILLO, Apparício. Alma pampa. Porto Alegre: Martins, 1984.

RILLO, Apparício. São Borja aqui te canto. s. 1.: Ed. Gráfica A Notícia, 1970.

RILLO, Apparício. Doze mil rapaduras e outros poemas. Porto Alegre: Tchê, 1984.

RILLO, Apparício. Trinta anos de poesia. Porto Alegre: Tchê, 1988. 